\title{
LA PANDEMIA DE LA COVID-19, LA FUERZA MAYOR Y LA ALTERACIÓN DE LAS CIRCUNSTANCIAS EN MATERIA CONTRACTUAL
}

\author{
Enrique Varsi Rospigliosi ${ }^{1}$, Nelson Rosenvald ${ }^{2}$, Marco Andrei Torres Maldonado²
}

Resumen: La declaratoria del estado de emergencia, a causa de la pandemia de la covid-19, exige un análisis de la vigencia de las relaciones contractuales y cómo estas pueden verse afectadas por eventos extraordinarios, imprevisibles e irresistibles que impidan el cumplimiento de las prestaciones, así como aquellos casos en los que la alteración de las circunstancias puede llevar a que una de las partes exija al juez recomponga el contenido de la prestación pactada o la resolución del contrato.

Palabras clave: fuerza mayor, alteración de las circunstancias, covid-19, eximentes de responsabilidad, imposibilidad de cumplimiento, teoría de la imprevisión

\section{The covid-19 pandemic, force majeure and changed contractual circumstances}

Abstract: The declaration of a state of emergency due to the covid-19 pandemic requires an analysis of the validity of the contractual relations and how these may be affected by extraordinary, unforeseeable and irresistible events that prevent the performance of the services, as well as those cases in which the alteration of circumstances may lead one of the parties to demand that the judge recompose the content of the agreed service or terminate the contract.

Keywords: impossibility, force majeur, hardship, covid-19, excuse for non-performance, impossibility of fulfilment, theory of unforeseen events

\section{A pandemia da covid-19, a força maior e a alteraçáo das circunstâncias em matéria contratual}

Resumo: A declaração de estado de emergência, devido à pandemia da covid-19, exige uma análise da vigência das relaçôes contratuais e como estas podem ser afetadas por eventos extraordinários, imprevisíveis e irresistíveis que impeçam o cumprimento das benefícios, assim como aqueles casos em que a alteração das circunstâncias podem levar a que uma das partes exija que o juiz recomponha o conteúdo da benefício acordada ou a rescisão do contrato.

Palavras chave: força maior, alteração das circunstâncias, covid-19, isenção de responsabilidade, impossibilidade de cumprimento, teoria da imprevisibilidade

\footnotetext{
${ }^{1}$ Universidad Nacional Mayor de San Marcos, Perú. Facultad de Derecho de la Universidad de Lima, Perú. RENACYT (P0010485) del CONCYTEC, Perú. Grupo de Investigación en Derecho Civil del Instituto de Investigación Científica de la Universidad de Lima, Perú Correspondencia: enriquevarsi@gmail.com

${ }^{2}$ Grupo de Investigación en Derecho Civil del Instituto de Investigación Científica de la Universidad de Lima, Perú
} 


\section{Introducción}

La covid-19 es una enfermedad infecciosa, altamente contagiosa, propiamente una pandemia, que se ha extendido por todo el mundo, a lo largo y ancho, sin distinción de regiones, sexos ni razas, y que está acabando con la vida de miles de personas. Los estragos que causa nos hacen pensar en una Tercera Guerra Mundial, en la que el enemigo es invisible, sin nacionalidad, no respeta fronteras y ataca sin piedad.

La repercusión de la covid-19 como hecho jurídico (involuntario) es enorme, sin precedentes ni proyecciones, impacta la teoría general de Derecho, abuso del derecho, del comportamiento leal, de la autonomía de la voluntad, de la buena fe; en la vida del hombre en su aspecto personal, en sus derechos, como la vida, libertad, salud, integridad, intimidad, actos de libre disposición del cuerpo humano, manejo de datos personales, datos sensibles, honor, identidad personal, uso de imagen y voz, etc., (Personas), en su vida de interrelación familiar, celebración del matrimonio (a distancia, por poder, matrimonio in mortis causae), formalización express de uniones estables, cambio de régimen patrimonial matrimoniales, violencia familiar, tenencia compartida, régimen de visitas, deber de asistencia y cuidados parentales, alimentos, presencia de los nuevos integrantes —abuelos (Familia), los actos de última voluntad en estados de emergencia, testamento vital (Sucesiones), en su relación con los bienes, el ejercicio de atributos del derecho de propiedad, posesión, vecindad, inmisiones y la modificación de garantías mobiliarias e hipotecarias (Reales), en sus relaciones económicas a causa de inejecuciones por fuerza mayor, lucro cesante, daño emergente, mora (Obligaciones), función social, el cambio de circunstancias reflejados en la teoría de la imprevisión, desequilibrio económico, excesiva onerosidad de la prestación o lesión, enriquecimiento sin causa (Contratos), en los distintos actos jurídicos, como el suministro, arrendamiento, mutuo, locación de servicios, obras, hospedaje, seguros, etc. (Contratos especiales), ha determinado la suspensión de los plazos en general, actio nata (Prescripción y caducidad) y la afectación de intereses por infección que genera daños por omisión en la prevención de contagios de covid-19, daño moral coletivo, daño de peligro o de riesgo, supuestos de mala praxis durante la atención de pacientes infectados o, lo que resulta frecuente en otros ordenamientos jurídicos, las acciones colectivas (class action) por daños contra el gobierno chino por el brote de la epidemia y su impacto en diversas personas naturales o jurídicas (Responsabilidad civil).

El impacto de la covid-19 es transversal a las diversas materias del Derecho civil. Todo esto nos lleva a repensar las instituciones, las que deben comenzar y terminar siendo no solo protectoras, sino también preventivas ante estas eventualidades. Importa el sujeto, como ser actuante al que el Derecho protege, pero está también el medio de realización patrimonial, representado por los actos jurídicos patrimoniales sustentados en la autonomía privada y la buena fe. Por ello, es menester delinear mecanismos de tutela en materia contractual y de defensa de los derechos de la persona.

La covid-19 no solo acarrea costos humanos, deja también una secuela en los familiares de los contagiados, recuperados y fallecidos, que deberá ser evaluada y tenida en cuenta como una política de Estado. Asimismo, esta pandemia impacta de forma dramática en las relaciones comerciales, afectando los compromisos de las partes, pactados en diversas actos jurídicos y contratos, poniendo en riesgo su ejecución. Esto lleva a las partes a su revisión y, según el caso, a una eventual resolución.

\section{La llegada de la covid-19 al Perú: el Decreto Supremo No 044-2020-PCM}

La primera semana de enero de 2020 se detectó en China un nuevo coronavirus, responsable de un brote de neumonía, a finales de diciembre del 2019, en la localidad de Wuhan, capital de la provincia de Hubei, al oeste de Shanghái. Hasta febrero de 2020, su distribución geográfica nos indicaba que, por lo menos en veintitrés países, había casos confirmados; en la mayoría de las ocasiones, los pacientes procedían directamente del país oriental(1).

El pasado 6 de marzo del 2020, el gobierno del Perú anunció el primer caso de covid-19 en nuestro territorio. Días después, el 11 de marzo, la Organización Mundial de la Salud (OMS) calificó el 
brote de la covid-19 como una pandemia, pues se había extendido en más de cien países del mundo.

En nuestro medio, el número de casos continuó en aumento, lo que llevó a que el Estado peruano, mediante el Decreto Supremo No 044-2020PCM, publicado el 16 de marzo del 2020, declarara el estado de emergencia nacional por un plazo de 15 días calendario, y dispusiera el aislamiento social obligatorio (cuarentena) por las graves circunstancias a consecuencia del brote de la covid-19. Posteriormente, dicha medida fue extendida dos veces: la primera por 13 días adicionales y la segunda hasta el 26 de abril.

La covid-19, en su calidad y naturaleza de hecho jurídico involuntario, viene generando diversas consecuencias, que no solo se limitan a la afectación de la salud o la pérdida de la vida de muchas personas, sino que también tiene un importante impacto en la economía, que se sustenta en el tráfico contractual en su diversidad de formas (como la actividad minera, el transporte, el turismo, la construcción, etcétera).

La covid-19 también afecta los contratos y lo hace sobremanera. Los efectos de la declaratoria de cuarentena de la sociedad en general no se limitan a la ejecución contractual, también alcanzan a la etapa formativa del contrato (tratativas o negociaciones que se ven afectadas). Sin embargo, es de interés analizar el impacto que genera a los contratos cuya ejecución se venía realizando de manera normal. En concreto, plantearemos algunas preguntas que iremos comentando en las siguientes líneas.

\section{La declaratoria de cuarentena, en virtud del Decreto Supremo No 044-2020-PCM, ¿̨consti- tuiría un supuesto de fuerza mayor?}

Determinar si la declaratoria de cuarentena, a causa de la pandemia de la covid-19, constituye un supuesto de fuerza mayor, dependerá de la regla contractual fijada por las partes o, en su defecto, de la regla legal prevista en el artículo 1.315 del Código Civil. Y es que se tiene como base del Derecho contractual el principio pacta sunt servanda, el que viene siendo preservado no solo por hacer primar en la relación contractual la común intención de las partes para fijar la forma y el contenido del contrato (artículo 1.354), sino también porque inspira a la economía de mercado.

Conforme al artículo 1356 del Código Civil,

"las disposiciones de la ley sobre contratos son supletorias de la voluntad de las partes, salvo que sean imperativas».

Por ende, es la autonomía privada la que, como regla general, configura el contenido y las consecuencias de la fuerza mayor. Las partes tiene la posibilidad de regular la asignación de riesgos que se puedan derivar de un supuesto de fuerza mayor.

Dado que el artículo 1315 del Código Civil no es una norma imperativa, resulta válido y eficaz que las partes puedan regular el contenido, alcance y efectos de la fuerza mayor. En caso de que no exista una regulación negocial especial, generada por la autonomía de las partes, será de aplicación lo previsto en el texto del citado artículo:

«Caso fortuito o fuerza mayor es la causa no imputable, consistente en un evento extraordinario, imprevisible e irresistible, que impide la ejecución de la obligación o determina su cumplimiento parcial, tardío o defectuoso».

En atención a ello, la fuerza mayor se encuentra referida a todo evento extraordinario, imprevisible e irresistible, ajeno a la voluntad del deudor. El ordenamiento jurídico peruano, al menos desde el formante legislativo, utiliza de manera indistinta las expresiones caso fortuito (acto de la naturaleza o del divino [acts of God]) o fuerza mayor (mandato del gobierno [acts of Prince]). Dicha circunstancia es sobreviniente al perfeccionamiento del contrato e impide, en atención a las circunstancias propias del contrato, que una de las partes o ambas ejecuten de manera debida cada una de sus prestaciones.

En ese contexto, corresponde analizar si la cuarentena, a consecuencia de la covid-19, constituye un supuesto de fuerza mayor, para lo cual resulta necesario que, en atención a lo regulado en el artículo 1.315 del Código Civil —insistimos, ante la inexistencia de una regla contractual convenida por las partes-, determinemos si concurren cada 
uno de sus caracteres.

Es necesario precisar que el análisis que se propone es general, pues la calificación de si nos encontramos ante un caso de fuerza mayor dependerá de las circunstancias de la situación en concreto, el tipo contractual, su causa y la regulación otorgada por las partes en torno a su configuración y sus consecuencias. No resulta posible, en consecuencia, brindar una solución general, pues dependerá del caso específico.

Desde la perspectiva del artículo 1.315 del Código Civil, para encontrarnos ante una fuerza mayor deben presentarse los siguientes requisitos:

\section{Evento extraordinario}

Se trata de un acontecimiento que no es común; por ejemplo, que existan escasas posibilidades de que ocurra.

La declaratoria de cuarentena constituye un evento excepcional y, por tanto, extraordinario. ¿Cuál es la razón? Durante los últimos cincuenta años, en el Perú no se había declarado una cuarentena que impidiera que las personas naturales y jurídicas realizaran sus actividades o cumplieran prestaciones a las que se habían obligado. Como acertadamente se ha indicado, la declaratoria de cuarentena general «no forma parte del entramado de situaciones racionalmente probables en circunstancias normales» (2).

La inmovilización obligatoria conlleva la restricción del libre tránsito, lo que supone un quebrantamiento del orden normal y cotidiano de las cosas. La regla general, que ha permanecido en el tiempo, siempre había sido la libertad de tránsito de las personas. Entonces, sin perjuicio del análisis del caso concreto, la cuarentena es un evento extraordinario.

\section{Evento imprevisible}

Significa que no pudo haber sido anticipado, pronosticado en sí.

La imprevisibilidad camina al lado de los deberes de diligencia, prudencia y cuidado. Esto quiere decir que el evento no solo debe revestir la objetividad en sí mismo como hecho extraordinario
- lo cual se demuestra sin mayores problemas al analizar la frecuencia o habitualidad del suceso-, sino que, además, requiere del elemento inherente al individuo, relativo a la conducta diligente que se espera de él(3).

$\mathrm{Al}$ respecto, según la jurisprudencia peruana,

«si el suceso que interrumpe la ejecución de la prestación se torna frecuente, siendo repetitivo, usual y común, desvirtúa la imprevisibilidad del hecho, en tanto la frecuencia y reiterancia de los hechos aporta la posibilidad de prever»(4).

Por lo demás, la declaratoria de cuarentena que pudiera invocarse, ¿era conocida o cognoscible al momento del perfeccionamiento del contrato?

Según una atenta doctrina,

«no parece haber claridad en todo el mundo acerca de la duración y los efectos de la pandemia (ni del encierro cuarentenal correlativo), o de las medidas económicas correspondientes. Por lo tanto, tampoco hay certeza acerca de los efectos jurídicos de las declaraciones de estados de excepción que limitan la movilidad, la prestación de servicios o la producción de bienes»(5).

Entonces, ¿la declaratoria de cuarentena general era un evento previsible? Aun cuando algunos puedan considerar que, dado que la existencia de la covid-19 en otros países ya había obligado a algunos Estados a adoptar medidas de ese tipo, consideramos que no era un evento previsible. En nuestro territorio no se había dado ninguna medida en ese sentido anteriormente.

El impacto de la covid-19 es nuevo. Al menos in abstracto, no era posible prevenir tal escenario. Es más, su carácter y calificación de pandemia se le otorga por esta imprevisibilidad respecto de la forma de expandirse, su tratamiento y su cura. Siendo ello así, no existía posibilidad alguna de prever la declaración de cuarentena, por lo que configura un evento imprevisible para las partes. Téngase en cuenta que lo imprevisible de un caso fortuito o de fuerza mayor hoy no trasciende gracias a la información y a la tecnología de la que disponemos(6), situación que no es aplicable a todos los casos ni sectores. 


\section{Evento irresistible}

La irresistibilidad hace referencia a que las consecuencias del evento no puedan ser controladas. No resulta posible realizar algo para contrarrestar los efectos del evento. De ese modo, la irresistibilidad «imposibilita absolutamente el cumplimiento de la prestación»(7).

Alterini, Ameal y López(8) señalan, refiriéndose al requisito de irresistibilidad, que esta se da cuando el deudor no puede evitar el acaecimiento del evento, a pesar de hacer todos los esfuerzos posibles. ¿La declaratoria de cuarentena constituye un evento irresistible? Consideramos que, sin perjuicio del análisis del caso concreto, sí constituye un evento irresistible. Cabe precisar que, la declaratoria de cuarentena general no genera que el cumplimiento de todas las prestaciones resulte irresistible. Es necesario identificar el modo cómo el evento de fuerza mayor impide el cumplimiento de una obligación, toda vez que existen prestaciones que, por tratarse de servicios esenciales, pueden ser ejecutados con total normalidad.

Sin embargo, posiblemente en la mayoría de los casos, las consecuencias de la declaratoria de cuarentena suponen un aislamiento social obligatorio, situación que no puede ser contrarrestada por el deudor de la prestación. Existe una imposibilidad evidente, lo que conoce hoy en el common law como "impracticabilidad". Por ende, nos encontraríamos ante un evento irresistible, pese a los mejores esfuerzos de las partes para cumplir con sus prestaciones.

Como puede apreciarse, la declaratoria de cuarentena, en virtud del Decreto Supremo No 0442020-PCM, y como consecuencia del impacto de la covid-19, desde un análisis general, reuniría cada uno de los requisitos de un evento de fuerza mayor. La cuestión de la fuerza mayor, como un evento externo, inevitable y ajeno a las acciones de las partes, podría conllevar a que estas no puedan honrar las prestaciones derivadas del contrato.

En general, las guerras, los disturbios, las revoluciones, las explosiones, las huelgas, los bloqueos de puertos, las acciones del gobierno (estados de emergencias) o los desastres naturales (como las inundaciones, los terremotos y los tsunamis) pue- den ser eventos de fuerza mayor. El deudor que no pueda cumplir sus obligaciones por razones $\tan$ extraordinarias como estas u otras puede alegar la existencia de un evento de caso fortuito o fuerza mayor.

En Nigeria, por ejemplo, donde los oleoductos y gasoductos pueden ser objeto de sabotaje, la venta de petróleo está ocasionalmente sujeta a la cláusula de la fuerza mayor, exonerante de responsabilidad. Las minas australianas de mineral de hierro y carbón son pasibles de inundación, lo que lleva a los productores a acordar una cláusula de fuerza mayor.

En el ámbito empresarial, las compañías han comenzado a invocar la fuerza mayor en respuesta a las dificultades que genera la covid-19. El gobierno chino está emitiendo los llamados «FM certificates» a las empresas que no pueden cumplir con sus obligaciones, a fin de apaciguar las reclamaciones por incumplimiento de contrato. Cabe indicar que, a medida que el coronavirus se ha propagado a otros países y continentes, es cuestionable si este certificado que acredita la fuerza mayor será efectivo para la protección de las empresas que intentan cumplir sus obligaciones.

Independiente de ello, como lo hemos señalado, debe demostrarse que la declaratoria de cuarentena, debido a la expansión de la covid-19, es la causa exclusiva del incumplimiento, pues existen algunas prestaciones que se realizan con total normalidad, dado que se encuentran exceptuadas (por ejemplo, el suministro o la venta de alimentos, etc.).

Dicho análisis implica la revisión de las circunstancias de hechos concretos, el tipo contractual involucrado y lo acordado por las partes en torno a los riesgos derivados del tratamiento de la fuerza mayor. De modo que quien pretenda beneficiarse de la fuerza mayor

"deberá actuar con cautela, y guardar prueba documental o de otro tipo de que actuó con la debida diligencia, y de que tomó todas las medidas a su alcance para la prevención o mitigación de los daños. No debe probar el hecho notorio de la pandemia, sino de la afectación del fenómeno a la imposible prestación o cumplimiento de su obligación contractual»(9). 
¿Qué efectos genera la declaratoria de cuarentena, en virtud del Decreto Supremo No 0442020-PCM y sus diversas ampliaciones, en su calidad de caso fortuito o fuerza mayor?

Sin perjuicio del efecto normal previsto por la regla legal (artículo 1.315) de la fuerza mayor — salvo regulación distinta de las partes_, que implica exonerar de cualquier responsabilidad al deudor de la prestación, con frecuencia, una de las consecuencias de la fuerza mayor consiste en la posibilidad de suspender el plazo que tenía una de las partes para ejecutar su obligación; o, incluso, resolver el contrato.

En relación con lo primero, las partes pueden acordar que - en aras de velar por la conservación del contrato- la fuerza mayor conlleve a extender la vigencia del plazo contractual, en caso la declaratoria de cuarentena, como consecuencia de la expansión de la covid-19, impida que el deudor cumpla con las obligaciones que forman parte de la integridad del contrato.

En caso de que se presente tal situación, el periodo de suspensión debería ser agregado al plazo de la vigencia del contrato. Ello implicaría un interés de las partes en buscar la preservación del vínculo contractual. Ello quiere decir que, aun cuando nos encontremos ante una inejecución parcial, tardía o defectuosa de la obligación, debido a una fuerza mayor, las partes pueden realizar sus mejores esfuerzos para ejecutar la obligación adicionando el plazo que se vio afectado.

\section{¿Puede una de las partes, en atención a dicha situación, exigir la resolución del contrato?}

De manera excepcional, las partes pueden convenir que, si el impedimento se prolonga durante un determinado número de días, la parte que se vea perjudicada podrá solicitar la resolución del contrato. Al respecto, el artículo 1.316 del Código Civil establece lo siguiente:

«La obligación se extingue si la prestación no se ejecuta por causa no imputable al deudor».

Si dicha causa es temporal, el deudor no es responsable por el retardo mientras ella perdure. Sin embargo, la obligación se extingue si la causa que determina la inejecución persiste hasta que, al deudor, de acuerdo con el título de la obligación o a la naturaleza de la prestación, ya no se le pueda considerar obligado a ejecutarla o, hasta que el acreedor, justificadamente, pierda interés en su cumplimiento o ya no le sea útil.

También se extingue la obligación, que solo es susceptible de ejecutarse parcialmente, si ella no fuese útil para el acreedor o si este no tuviese justificado interés en su ejecución parcial. En caso contrario, el deudor queda obligado a ejecutarla con reducción de la contraprestación si la hubiere.

La aplicabilidad de dicho artículo implicará valorar la declaratoria de cuarentena y su impacto en el contrato en específico. Como hemos advertido, una vez superados todos los obstáculos, con frecuencia la cláusula de la fuerza mayor suele describir el escenario posterior al hecho, que no siempre será el final del contrato, referido a una suspensión contractual o una obligación de renegociación. Sin embargo, también podrá conllevar a que se ejerza el derecho a resolver el contrato.

\section{¿Puede una de las partes exigir al juez la reduc- ción o el aumento de la contraprestación del contrato o, en su caso, la resolución?}

Puede ocurrir que la prestación se torne dificultosa de ejecutar por la declaratoria del aislamiento social obligatorio a causa de la covid- 19 .

Frente a ello, la parte perjudicada podría solicitar al juez o árbitro la reducción de la prestación o el aumento de la contraprestación o, incluso, que el contrato pueda ser resuelto. Lo mencionado tiene relación con la alteración de las circunstancias en las que se ejecuta el contrato y con la imprevisión de lo gravoso que pueden tornarse las prestaciones, ya que terminan siendo más onerosas o menos deseables de lo que se había previsto. Se llama excesiva onerosidad y se sustenta en la figura de la imprevisión contractual (rebus sic stantibus). El Código Civil trata esta institución en el artículo 1.440:

«En los contratos conmutativos de ejecución continuada, periódica o diferida, si la prestación llega a ser excesivamente onerosa por acontecimientos extraordinarios e imprevisibles, la parte perjudi- 
cada puede solicitar al juez que la reduzca o que aumente la contraprestación, a fin de que cese la excesiva onerosidad.

Si ello no fuera posible por la naturaleza de la prestación, por las circunstancias o si lo solicitara el demandado, el juez decidirá la resolución del contrato. La resolución no se extiende a las prestaciones ejecutadas».

En este escenario, no es requisito que la prestación resulte imposible, sino que implique una alteración grave de las bases y el equilibrio del contrato. Al igual que el análisis realizado en relación con la fuerza mayor, la valoración de la excesiva onerosidad de la prestación también deberá efectuarse en el caso concreto de la relación contractual. Asimismo, permite un respiro, un ajuste a la relación contractual y la salva del riesgo de acabamiento, al facultar al juez para llevar a cabo una revisión o, en caso extremo, aplicar la resolución del contrato.

\section{Derecho, bioética y pandemia}

El Derecho regula las relaciones humanas mediante leyes; estas tienen normas y principios que la inspiran, sustentados en criterios democráticos y de inclusión social; la bioética, en su rol cautelar de la conducta humana, se sustenta en lo clásicos principios de beneficencia, justicia y solidaridad. La pandemia que ataca a la humanidad debe ser tratada en su contexto social y biológico, amalgamando la ley con la ética en salvaguarda del bien común, con un correcto uso de los derechos de las personas, preservando su dignidad como máximo valor del hombre.

La pandemia de la covid-19 generará futuros conflictos sobre temas contractuales, respecto de los cuales el hombre tendrá intereses contrapuestos. Se deberá elegir, pues cualquier interés debe tutelarse. Según Montoliu, «estos dilemas son los que resuelve la ética, que analizará las circunstancias que hay detrás de cada uno, sus posibles beneficios y riesgos asociados y la legislación. Así emitirá un juicio razonado y una recomendación sobre el camino a seguir»(10).

Las controversias patrimoniales, a causa de la covid-19, son una manifestación de los conflictos de intereses que resultan connaturales al hombre, en los que la bioética tiene una especial relevancia. Así, «la evaluación ética es una reflexión crítica sobre la moralidad, un marco al que acudir para tomar la mejor decisión posible con nuestra escala de valores y con las normas existentes»(10).

Las medidas que adopten los Estados también deben tomar en cuenta criterios bioéticos, básicos y esenciales, con imperiosa razón, para la preservación del cuidado de la salud en situaciones extremas. Se busca el mayor beneficio del ser humano, evitando su afectación al derecho a la salud, así como a la vida. El impacto de la pandemia de la covid-19 en realidades que tienen un sistema de salud precario, por ejemplo, plantea el dilema sobre las personas que recibirán atención cuando exista escasez de equipos de respiración. La relación contractual médico-paciente se ve imbuida de otros factores, que necesariamente implican una perspectiva bioética.

Y es que, al final de todo, dada la función social de las instituciones de Derecho privado, la presencia del ser humano es trascendental en cualquier estudio, lo que hace indispensable la presencia de la bioética al momento de adoptar cualquier acción a futuro. Este es el mejor momento para demostrar que la incidencia y trascendencia de la ética en salud es un tema de interés en la política de los Estados.

\section{Conclusión}

La covid-19 es una pandemia que ataca la vida del hombre en todas sus dimensiones: biológica y social, económica y jurídica.

La determinación de si la declaratoria de cuarentena, debido a la expansión de la covid-19, conlleva a un supuesto de fuerza mayor, implicará la revisión de las circunstancias del caso concreto, el tipo contractual involucrado, su causa y lo acordado por las partes en torno a los riesgos y efectos derivados del tratamiento de la fuerza mayor.

En caso de que las partes no hubieran convenido una regulación respecto a la fuerza mayor, será de aplicación de manera supletoria lo previsto en el artículo 1.315 del Código Civil. El referido artículo consagra a la fuerza mayor (causa no imputa- 
ble) como un evento extraordinario, imprevisible e irresistible que podría conllevar a que el deudor se encuentre exento de responsabilidad.

Quien invoque la fuerza mayor debe acreditar clara y concretamente la manera en que la pandemia o, en su caso, las medidas adoptadas por el gobierno afectan la posibilidad de cumplimiento del contrato.

Pero la invocación de la fuerza mayor no es el único remedio contractual. Puede ocurrir que la prestación se torne excesivamente onerosa por la declaratoria del aislamiento social obligatorio a causa de la covid-19. Frente a ello, la parte perjudicada puede solicitar al juez o árbitro la reducción de la prestación o el aumento la contraprestación; o, incluso, que el contrato sea resuelto.

Los innumerables conflictos jurídicos post co- vid-19 son una realidad que se avecina. Ello es un reto para la profesión, para el sistema judicial y arbitral, para el Derecho en sí y para todos y cada uno sus protagonistas. Debemos estar preparados y sacar una lección de esta crisis: somos más fuertes que ella, debemos actuar con solidaridad y con el máximo respeto por la dignidad del ser humano.

\section{Agradecimientos}

Esta investigación ha contado con la colaboración de Mariana Aguilar Ávila, estudiante de Derecho de la Universidad de Lima, Perú.

\section{Referencias}

1. Moreno J. El desafío de comunicar y controlar la epidemia por coronavirus. Biomédica 2020; 40: 11-13.

2. Zecenarro C. Enfoque derecho. Abril del 2020 [11 de abril del 2020]. Disponible en: https://www.enfoquederecho. com/2020/04/10/impacto-del-estado-de-emergencia-por-el-covid-19-en-los-contratos-con-prestaciones-reciprocas/

3. Osterling F, Castillo M. Compendio de derecho de las obligaciones. Lima: Palestra Editores; 2008.

4. Corte Suprema de Justicia de la República. Casación N 1764-2015, Lima, del 15/09/2016. Pasión por el Derecho [Internet]. Viernes, 2 de agosto del 2019, [9 de abril del 2020]. Disponible en: https://static.legis.pe/wp-content/uploads/2019/08/Casacion-1764-2015-Lima-Legis.pe_.pdf

5. Aramburu M. Pandemia y fuerza mayor (Legis Ámbito Jurídico). Marzo del 2020. [25 de marzo del 2020]. Disponible en: https:/www.ambitojuridico.com/noticias/columnistas/administrativo-y-contratacion/pandemia-y-fuerza-mayor-maximilianoaramburo?fbclid=IwAR0dWPcrwTmfKCQhGjm3bW6OQxce50XuBOPblIIZIKjzwxsvOyVkGDVJ5O0.

6. Vega Y. El coronavirus y la fuerza mayor. LP Pasión por el Derecho. Marzo del 2020 [16 de marzo del 2020]. Disponible en: https://lpderecho.pe/coronavirus-fuerza-mayor-yuri-vega-mere/.

7. Corte Suprema de Justicia de la República. Casación N No 1693-2014, Lima, del 8/3/2016. El Peruano [Internet]. Lunes 30 de enero de 2017, [8 de abril del 2020]; 86783-86785. Disponible en: https://img.lpderecho.pe/wp-content/uploads/2017/02/ Casación-1693-2014-Lima-Corte-Suprema-establece-diferencia-entre-caso-fortuito-y-fuerza-mayor.pdf

8. Alterini A, Ameal O, López R, (eds). Curso de obligaciones. Tomo I. Buenos Aires: Editorial Abeledo-Perrot; 1988.

9. Simmons \& Simmons (Law Firm). Fuerza mayor: Acontecimiento imprevisible e inevitable (Simmons-simmons Law Firm). Marzo del 2020 [13 de marzo del 2020]. Disponible en: https://www.simmons-simmons.com/en/publications/ck7q9h0eq0z0r0905oo65ejty/sobre-la-incidencia-de-las-medidas-gubernamentales-tomadas-con-ocasi-n

10. Montoliu L. En una pandemia mantener la bioética es más importante que nunca (The conversation). Marzo del 2020 [11 de abril de 2020]. Disponible en: https://theconversation.com/en-una-pandemia-mantener-la-bioetica-es-mas-importante-quenunca-134449

Recibido: 9 de abril de 2020

Aceptado: 29 de abril de 2020 